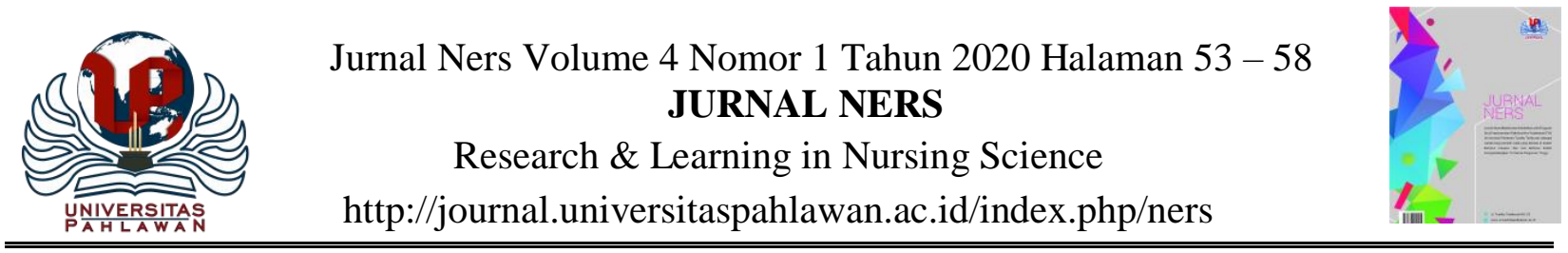

\title{
PENGARUH SENAM DIABETIK TERHADAP PENURUNAN KADAR GULA DARAH PADA PENDERITA DM TIPE II DI WILAYAH KERJA PUSKESMAS BANGKINANG KOTA TAHUN 2018
}

\author{
Nislawaty \\ Universitas Pahlawan Tuanku Tambusai \\ email: nislawaty@gmail.com
}

\begin{abstract}
Abstrak
Data dari Internatonal Diabetes Federatiaon (IDF) tingkat prevalensi global penderita DM tipe II pada tahun 2013 berjumlah 382 juta kasus, pada tahun 2013 penyakit diabetes mellitus berjumlah 387 juta kasus dan pada tahun tahun 2035 jumlah insiden DM DM tipe II akan mengalami peningkatan menjadi 55\% (592 juta) di antara usia penderita DM 40-59 tahun. Tujuan penelitian ini adalah untuk mengetahui pengaruh senam diabetik terhadap penurunan kadar gula darah pada penderita DM Tipe II di wilayah kerja Puskesmas Bangkinang Kota tahun 2018. Jenis penelitian ini adalah pre eksperimet dengan rancangan one group pretest postest. Populasi dalam penelitian ini adalah penderita diabetes mellitus Tipe II di wilayah kerja Puskesmas Bangkinang Kota berjumlah 66 orang dengan dengan teknik pengambilan sampel total sampling. Alat pengumpulan data yang digunakan yaitu berupa lembar checklist Analisa yang digunakan dalam penelitian ini adalah analisa univariat dan bivariat. Hasil penelitian terdapat pengaruh pemberian senam diabetik terhadap penurunan kadar gula darah di wilayah Kerja Puskesmas Bangkinang kota tahun 2018 dengan p value 0,000. Diharapkan bagi responden untuk selalu menjaga pola makan agar kadar gula darah tetap dalam batas normal dan bagi penderita DM Tipe II agar rutin melakukan senam diabetik untuk menurunkan kadar gula darah.
\end{abstract}

Kata Kunci : Senam Diabetik, DM Tipe II

Daftar Bacaan : 29 ( $2008-2017)$

$\triangle$ Corresponding author :

Address : Jl. Tuanku Tambusai No. 23 Bangkinang

Email : nislawaty@gmail.com

Phone : 085271096011 


\section{PENDAHULUAN}

Diabetes Mellitus (DM) adalah salah satu jenis penyakit degenerative yang mengalami peningkatan setiap tahun di negara- negara seluruh dunia.Diabetes Mellitus (DM) merupakan penyakit gangguan metabolisme yang bersifat kronis dengan karakteristik hiperglikemia. Berbagai komplikasi dapat timbul akibat kadar gula darah yang tidak terkontrol, misalnya neuropati, hipertensi, jantung koroner, retinopati, nepropati, gangren, dan lainlain. Kadar gula darah dapat dikendalikan melalui diet, olah raga, dan obat- obatan.Upaya mencegah terjadinya komplikasi kronis, diperlukan pengendalian DM dengan baik. Sasaran dengan kriteria nilai baik untuk diabetes diantaranya gula darah $80-200 \mathrm{mg} / \mathrm{dL}$, trigliserida $<150 \mathrm{mg} / \mathrm{dL}$, IMT 18,5-22,9 kg/m2 dan tekanan darah 130/80 mmHg (Perkeni,2012 dalam Astuti 2016).

Diabetes melitus dibagi menjadi tipe 1 dan tipe 2.Tipe 1 terjadi kelainan sekresi insulin oleh sel $\beta$ pankreas.Pasien DM pada tipe ini mewarisi kerentanan genetik yang merupakan predisposisi untuk kerusakan autoimun sel $\beta$ pankreas.Tipe 2 jumlah insulin normal, tetapi jumlah reseptor insulin yang terdapat pada permukaan sel yang kurang, sehingga glukosa yang masuk ke dalam sel sedikit dan glukosa dalam darah menjadi meningkat (Smeltzer, 2002 dalam Rahmi 2015).

Data dari Internatonal Diabetes Federatiaon (IDF) tingkat prevalensi global penderita DM tipe II pada tahun 2013 berjumlah 382 juta kasus, pada tahun 2013 penyakit diabetes mellitus berjumlah 387 juta kasus dan pada tahun tahun 2035 jumlah insiden
DMDM tipe II akan mengalami peningkatan menjadi 55\% (592 juta) di antara usia penderita DM 40-59 tahun (IDF, 2015 dalam Permatasari 2016).

Indonesia merupakan negara urutan ketujuh dengan kejadian diabetes mellitus tertinggi di dunia dengan jumlah 8,5 juta penderita (Astuti, 2016). Indonesia merupakaan salah satu dari 10 negara dengan jumlah penderita diabetes terbanyak.Indonesia menempati urutan ke-4 penderita DM di dunia setelah India, Cina, dan Amerika. Pada tahun 2000 dengan prevalesi DM mencapai 8,4 juta orang, pada tahun 2013 Indonesia menempati urutan ke-7 penderita diabetes mellitus untuk usia 20-79 tahun dan diperkirakan pada tahun 2030 Indonesia akan tetap berada dalam sepuluh besar negara dengan prevalensi DM tertinggi di dunia (Suryani, 2014)

Menurut Suryani (2014) prevalensi DM DM tipe II di Provinsi Riau berdasarkan Riskesdas 2013 mencapai 1,2 \% dengan penderita DM terbanyak adalah usia 55-64 tahun dan didominasi oleh penderita DMDM tipe II perempuan, sedangkan prevalensi DM DM tipe II di Kota Pekanbaru mencapai 0,9 \%. Di RSUD Arifin Achmad Provinsi Riau, DM DM tipe II termasuk ke dalam 15 penyakit terbesar di bagian penyakit dalam. Data diabetes melitus DM tipe II di Kabupaten Kampar. bahwa Bangkinang Kota mensuduki peringkat pertama tertinggi. Olahraga senam diabetik dapat mengatur gula darah melalui tiga mekanisme yaitu perangsangan akut transport gula otot, penguatan akut kerja insulin dan up- regulation jalur jangka panjang insulin signal. Perbaikan kepekaan insulin merupakan dampak dari afinitas reseptor insulin, pengendalian gula mengarah pada penundaan penebalan membran basal pembuluh darah (Giri, 
2013).

Olahraga senam diabetic dalam DM tipe II berperan utama dalam pengaturan kadar gula darah. Pada tipe ini produksi insulin umumnya tidak terganggu terutama pada awal menderita penyakit ini.Masalah utama adalah kurangnya respons reseptor insulin terhadap insulin, sehingga insulin tidak dapat masuk ke dalam selsel tubuh kecuali otak.Otot yang berkontraksi atau aktif tidak memerlukan insulin untuk memasukkan glukosa ke dalam sel, karena pada otot yang aktif sensitivitas reseptor insulin meningkat. Oleh karena itu olahraga pada DM tipe II akan menyebabkan berkurangnya kebutuhan insulin eksogen. Dengan demikian DM tipe II tidak disebabkan kurang atau tidak adanya produksi insulin tetapi disebabkan karena kurangnya respons reseptor insulin terhadap insulin, sehingga dengan berolahraga secara teratur dapat menurunkan kadar glukosa dalam darah (Ermita, 2015).

Hasil penelitian yang telah dilakukan oleh Ocbrivianita Mulyaningtyas Utomo, et al tahun 2012, terdapat perbedaan kadar gula darah sewaktu sebelum dan sesudah intervensi senam diabetes pada kelompok senam. Penurunan rata-rata gula darah pada kelompok senam 2,3 kali lebih besar daripada kelompok tidak senam.

Berdasarkan survey awal yang peneliti lakukan di Posyandu Melati wilayah kerja Puskesmas Bangkinang terhadap 10 orang penderita DM didapatkan hasil bahwa 10 orang lansia tidak mengetahui bahwa senam diabetic dapat menurunkan kadar gula darah,Dari 10 orang lansia ini mengikuti senam diabetic selama 3 kali seminggu dan ketika dilakukan pengecekan kadar gula darah pada minggu kedua setiap bulan, didapatkan data bahwa 6 dari 10 orang mengalami penurunan kadar gula darah.

Berdasarkan latar belakang diatas maka peneliti tertarik untuk melakukan penelitian dengan judul "Pengaruh senam diabetik terhadap penurunan kadar gula darah pada penderita diabetes mellitus Tipe II di Posyandu Melatiwilayah kerja Puskesmas Bangkinang Kota tahun 2018.

Tujuan penelitian ini untuk mengetahui Pengaruh senam diabetik terhadap penurunan kadar gula darah pada penderita DM Tipe II di Posyandu Melati wilayah kerja Puskesmas Bangkinang Kota tahun 2018

\section{METODE PENELITIAN}

Jenis penelitian ini menggunakan metode praeksperimen dengan rancangan one group pretestposttest.Rancangan ini juga tidak ada kelompok pembanding (control), desain yang dilakukan dengan cara melakukan observasi sebanyak 2 kali yaitu sebelum dan setelah diberikan tindakan (Notoatmodjo, 2010). Metode ini digunakan untuk melihat pengaruh senam diabetic terhadap penurunan kadar gula darah di wilayah kerja puskesmas Bangkinang kota.

Rancangan penelitian yang dibuat oleh peneliti untuk mempermudah peneliti dalam melakukan penelitian adalah sebagai berikut :

Skema 3.1

Rancangan Penelitian

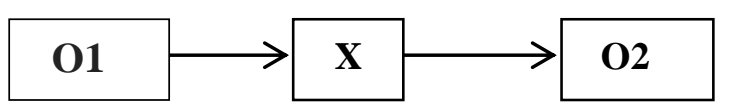

Keterangan :
O1 : Nilai
pretest (sebelum diberikan senam diabetik)
$\mathbf{X}$ : Perlakuan yang diberikan (pemberian senam diabetik) 
O2 : Nilai posttest setelah diberikan senam diabetik

O2-01: Perbedaan kadar gula darah sebelum dan setelah diberikan senam diabetik

\section{HASIL DAN PEMBAHASAN}

Hasil penelitian terdapat pengaruh pemberian senam diabetik terhadap penurunan kadar gula darah di wilayah Kerja Puskesmas Bangkinang kota tahun 2018 dengan $\mathrm{p}$ value 0,000. Diharapkan bagi responden untuk selalu menjaga pola makan agar kadar gula darah tetap dalam batas normal dan bagi penderita DM Tipe II agar rutin melakukan senam diabetik untuk menurunkan kadar gula darah.

\section{KESIMPULAN DAN SARAN}

Dari hasil penelitian yang dilakukan dengan judul "pengaruhsenam diabetikterhadap penurunan kadar gula darah pada penderita Diabetes Melitus tipe II di Wilayah Kerja Puskesmas Bangkinang Kota tahun 2018 dapat diambil kesimpulan sebagai berikut :

1. Rata- rata kadar gula darah sebelum diberikan senam diabetikadalah 250,32

2. Rata- rata kadar gula darah sesudah diberikan senam diabetikadalah 218,98

Terdapat

pengaruhsenam diabetikterhadap penurunan kadar gula darah pada penderita Diabetes Melitus tipe II di Wilayah Kerja Puskesmas Bangkinang Kota tahun 2018 nilai p value $\leq 0,05$.

Adapun saran dari penelitian ini meliputi:

\section{Bagi Responden}

Diharapkan bagi responden untuk selalu menjaga pola makan agar kadar gula darah tetap dalam batas normal dan bagi penderita DM Tipe II agar rutin melakukan senam diabetik untuk menurunkan kadar gula darah.

\section{Bagi Puskesmas Bangkinang Kota}

Hasil penelitian ini diharapkan dapat memberikan kebijakan bagi Puskesmas dalam penatalaksanaan non farmakologi DM Tipe II dan wawasan baru dan menambah ilmu pengetahuan bagi petugas di Puskesmas sebagai bahan tambahan dalam menurunkan kadar gula darah

3. Bagi Universitas Pahlawan Tuanku

\section{Tambusai}

Hasil penelitian ini dapat dapat menjadikanpenelitian ini sebagai sumber referensi dalam melakukan penelitian dan meneliti tanaman lain yang dapat menurunkan kadar gula darah pada penderita diabetes mellitustipe

IIdenganmetodepenelitianyang berbeda.

\section{Bagi Pelitian Selanjutnya}

Bagi penelitian selanjutnya agar dapat melakukan penelitian faktorfaktor yang bisa mempengaruhi penurunan kadar gula darah, dan bisa lebih menekankan diet padapenderita diabetes.

\section{Bagi Peneliti}

Hasil penelitian ini dapat menambah wawasan dan pengetahuan bagi peneliti sebagaiterapi non farmakologi dalam menurunkan kadar gula darah pagi penderita DM Tipe II.

\section{DAFTAR PUSTAKA}

American Diabetes Association. (2012).

Diabetes Care. Diakses pada 17/09/2016 dari

http://www.ncbi.nlm.nih.gov. diakses tanggal 13 April 2018

Arif. (2009). Penanganan penyakit diabetes melitus. Jakarta: Kanisius

Astuti.(2016). Pengaruh senam Aerobik terhadap Kadar Gula Darah Puasa Penderita DM Tipe II pada Prolanis di UPT Puskesmas Wonogiri 1.Dari http://digilib.stikeskusumahusada.a 
c.id/files/disk1/28/01-gdl-

dyahastuti-1390-1-0_naskah-h.pdf.

Diakses tanggal 11 April 2018

Djaja. (2014). Diabetes: Memerangi

Diabetes Melalui Diet Golongan

Darah dan Pola Makan yang

Benar. Yogyakarta: B-First.

Ernawati. (2013). Pengaruh Senam

Diabetes Mellitus Terhadap Kadar

Glukosa Darah Pada Penderita

Diabetes Mellitus Tipe 2 Di

Wilayah Kerja Puskesmas

Darusalalm Medan 2011. Tesis

tidak diterbitkan. Jurnal Mutiara

Ners. Diakses tanggal 13 Juli 2018

Firman. (2010).Pengobatan Alternatif Bagi

Diabetes, Fakultas Pendidikan

Kesehatan dan Rekreasi, UI. Jakarta

Giri.(2013). Hubungan dukungan keluarga tentang senam lansia dengan keaktifan mengikuti senam di posyandu "Peduli Insani" $d i$ Mendungan Desa Pabelan Kartasura. [skripsi]. [Surakarta] : Universitas Muhamadiyah Surakarta. Diakses tanggal 11 Mei 2018

Hasdiah. (2012). Olahraga pada lanjut usia (Lansia). Jakarta: PT Wijaya Kusuma

Harrison. (2012). Hidup Sehat dan Normal dengan Diabetes. Yogyakarta. Pustaka Media

Hidayat. (2014). Metode Penelitian Keperawatan dan Teknik Analisa Data. Jakarta: Salemba Medika

Kurniawan.(2012). Hubungan Latihan Jasmani Terhadap Kadar Glukosa Darah Penderita Diabetes Mellitus Tipe II. Surakarta: Universitas Negeri Sebelas Maret. Diakses tnggal 15 Juli 2018

Kemenkes RI. (2014). Penyakit Tidak Menular Penyebab Kematian Terbanyak di Indonesia.Dari http://www.depkes.go.id/index.pen yakit-tidak-menular-penyebabkematian-diindonesia.html. Diakses tanggal 12 April 2018

Mistra. (2013). Hidup sehat mandiri dengan diabetes melitus. Jakata: FKUI

Notoatmodjo.(2010). Promosi Kesehatan dan Ilmu Perilaku. Jakarta: Rineka Cipta.

Permatasari.(2016). Pengaruh Senam Bugar Lansia Indonesia Terhadap Penurunan Kadar Gula Darah Pada Wanita Lansia.Dari http://lib.unnes.ac.id/2348. Diakses tanggal 14 April 2018

Perkini.(2011). Konsensus pengelolaan dan pencegahan diabetes melitus di Indonesia.

Puskesmas Bangkinang Kota.(2017). Data Penderita DM di Wilayah kerja Puskesmas Bangkinang Kota. Diperoleh tangal 15 April 2018

Rachmawati. (2010). Pengaruh senam diabetic terhadap penurunan tingkat kadar gula darah orang lanjut usia. Diakses tanggal 13 Juli 2018

Rahmi. (2015). Pengaruh senam tai chi terhadap kadar gula darah pada lanjut

usia.Darihttp://digilib.unisayogya.a c.id/2923/1/naskah\%20publikasi.pd f. Diakses tanggal 11 April 2018

Ramadhani. (2016). Pengaruh senam lansia terhadap kadar gula darah lansiadi BPLU Senja Cerah Manado.Dari

https://media.neliti.com/ -pengaruhsenam-lansia-terhadap-kadar-

gul.pdf. Diakses tanggal 12 April 2018

Rahardja. (2012). Diabetes; Terapi dan Pencegahannya: P.A. Siboro, Indonesia Publising House. Bandung

Salindeho. (2016). Pengaruh Senam Diabetes Melitus Terhadap Kadar 
Gula Darah Penderita Diabetes Melitus Tipe 2 Di Sanggar Senam Kabupaten Gorontalo.Dari $\mathrm{http} / / \mathrm{https}: / /$ media.neliti.com/media /publications/107179-ID-pengaruhsenam-diabetes-melitusterhadap.pdf. Diakses tanggal 18 April 2018

Sanjaya.(2016). Pengaruh senam diabetic terhadap tekanan darah penderita diabetes mellitus tipe II di wilayah kerja Puskesmas Peterongan Kabupaten Jombang.Diakses tanggal 14 Juli 2018

Subis.(2010). Buku ajar Ilmu Penyakit Dalam. IV ed. Jakarta: Pusat penerbitan Ilmu Penyakit dalam FK UI

Suryani. (2014).

PengaruhLatihan Senam Diabetes

Melitus terhadap penderita DM pada Lanjut Usia (Lansia) di Kelurahan Gayam Kecamatan Sukoharjo.Dari

https://www.scribd.com/document/ 359211449/.Diakses tanggal 16 April 2018.

Saralagi.(2016). Evaluasi Kualitas Hidup Pasien Diabetes Militus Tipe 2. Jakarta: Pustaka Media

Tara, (2008). Patofisiologi Konsep Klinis

Proses - Proses Penyakit. Jakarta: Buku Kedokteran EGC

Tilarso.(2013). Pengaruh Senam

Lansia Terhadap Aktivitas Seharihari pada. Lansia di Desa Mijen Ungaran Kelurahan Gedanganak. Diakses tanggal 16 April 2018

Unairawati. (2011). Pengaruh senam diabetes terhadap penurunan kadar gula darah pada penderita diabetes di Puskesmas Bukateja Purbalingga. Diakses tanggal 15 Juli 2018. 